\title{
FORMAÇÃO DAS INSTITUIÇÕES DE ENSINO SUPERIOR NA DÉCADA DE 1930: INTERESSES POLÍTICOS E INTELECTUAIS
}

Hugo Loss

RESUMO: O objetivo deste trabalho é explorar como se manifestaram os interesses do grupo de intelectuais e do grupo político responsável pela fundação da USP, UDF e Escola Livre de Sociologia e Política de São Paulo na década de 1930. A controvérsia na bibliografia é constituída pelo embate entre perspectivas que, por um lado, afirmam que o campo intelectual e artístico foi amplamente cooptado pelo regime político que se instaurava, e por outro lado, uma perspectiva que defende que os intelectuais tinham alguma autonomia e que podiam manifestar certo "pensamento puro". Para realizar este trabalho analisamos as atas de fundação das respectivas instituições de ensino ao invés de estudar os agentes que atuavam na época. Nossa conclusão se aproxima mais da segunda perspectiva, quando notamos uma diferença na liberdade conforme os decretos de fundação de cada Universidade.

PALAVRAS-CHAVE: campo político, campo intelectual, Universidades.

\section{Introdução}

Este artigo pretende abordar a relação entre o campo político e o campo intelectual no Brasil da década de 1930. Para realizar este estudo analisamos os decretos de fundação de três instituições de ensino: USP, UDF e Escola Livre de Sociologia e Política de São Paulo. A importância de um estudo deste tipo é que conseguiremos evidenciar a relação entre intelectuais e políticos sob uma perspectiva institucional, verificando o peso de cada grupo no processo de construção material do Estado e do sistema de ensino superior.

Dividimos o trabalho em três partes: na primeira parte faremos uma discussão bibliográfica e iniciaremos a análise dos documentos, com o objetivo de identificar os interesses ligados a cada campo (intelectual e político) e a pertinência dos interesses intelectuais no 
processo de formação das Universidades. $\mathrm{Na}$ segunda parte mostraremos a ação ligada aos dois interesses no processo de construção das Universidades, lançaremos hipóteses sobre como os dois interesses agiram no processo de edificação das instituições. $\mathrm{Na}$ terceira parte faremos uma análise específica da formação e fechamento da UDF, mostrando como os intelectuais foram importantes para a formação das Universidades.

\section{Interesses políticos e interesses intelectuais}

A maioria estudos das relações entre o campo político e o campo intelectual da década de 1930 têm como principal objeto de análise os intelectuais da época (Francisco Campos, Oliveira Vianna, Gilberto Freyre, Azevedo Amaral, Candido Portinari, etc.) e como eles se relacionavam com um Estado da partir de 1930 (que estava em processo de centralização administrativa e de ampliação e complexificação de sua estrutura burocrática e institucional). A opinião preponderante nesses estudos é que os intelectuais foram em grande medida submetidos ao Estado. Em maior ou menor grau, a bibliografia defende a heteronomia do campo intelectual em relação ao campo político.

Ao estudar a revista "Cultura política" (que circulou na primeira metade da década de 1940 e que carrega fortes indícios de ter funcionado como "agência de propaganda" do regime do Estado Novo) Codato e Guandalini buscam identificar o "caráter complexo da incorporação dos intelectuais ao regime" do Estado Novo. ${ }^{1}$ Por meio da análise dos artigos veiculados pela revista e do perfil social de seus principais autores, Codato e Guandalini evidenciam como a própria produção literária e científica funcionaram como justificativas do regime político autoritário. Capelato, pesquisando a forma como os meios de comunicação (principalmente a imprensa e o rádio)

\footnotetext{
${ }^{1}$ CODATO, Adriano; GUANDALINI, Walter. Os autores e suas idéias: um estudo sobre a elite intelectual e o discurso político do Estado Novo. Estudos Históricos. Rio de Janeiro, v. 32, p. 145-164, 2003. p. 149.
} 
funcionavam para formular a legitimidade do Estado Novo, também constata uma forte dependência do campo jornalístico em relação ao campo político.

Embora haja um consenso na bibliografia de que a esfera estatal sobrepunha sua lógica à esfera intelectual, existem autores que buscam entender o campo intelectual não como um efeito direto do dinâmica política. Assim, ao contrário de Codato, Guandalini e Capelato, autores como Miceli e Bomeny atribuem uma maior autonomia à produção dos intelectuais no Estado Novo.

Em seu livro imagens negociadas Miceli demonstra como a produção artística de Portinari ao mesmo tempo em que era produzida para o Estado Novo guardava características próprias. Desta forma, ao guardar características próprias, não se pode dizer que há uma ausência completa de autonomia dos intelectuais. Segundo Miceli "o ponto de vista do artista é talvez a pista central do livro, no sentido de que a imagem que é negociada, a imagem de fato fabricada, é uma imagem onde o artista dá uma resposta em geral muito moleque e muito, digamos, desobediente às demandas do retratado", assim, por meio de uma obra artística ou intelectual "pode-se fazer com que eles [os artistas] transmitam uma certa resposta crítica à encomenda". 2

A abordagem que escolhemos se diferencia das citadas por ter como objeto de análise não os agentes, mas algumas instituições de ensino superior. Apesar desta diferença inicial, nos posicionamos ao lado de Miceli e Bomeny ao buscar identificar a relação de heteronomia e autonomia do campo intelectual em relação ao campo político. Acreditamos que por mais forte que se apresente o interesse político no momento de formação das Universidades, o interesse intelectual teve alguma participação. Com isso cremos que existe alguma especificidade do universo artístico e acadêmico que está livre de determinações políticas. A própria sensação produzida pela arte podem dizer algo que não se pode reduzir a relações causais que eliminem aquela ontologia.

${ }^{2}$ MICELI, Sérgio. A política cultural. In: PANDOLFI, Dulce (org). Repensando o Estado Novo. Rio de Janeiro, FGV, 1999. p. 191-196. p. 194-195. 
A hipótese que trabalhamos é que a fundação da USP, em 1934, e a fundação da Universidade do Distrito Federal, em 1935, são produtos de uma ligação entre dois interesses: político e intelectual, onde cada uma dessas substâncias contribuiu - em graus diferentes para a síntese de uma nova sustância: Universidades. Isto é, não ocorreu a predominância exclusiva de um dos interesses no processo de formação de uma ambiente universitário brasileiro.

Para realizar nosso estudo nos apoiamos em alguns postulados da teoria de Pierre Bourdieu. Primeiramente, foi necessário constatar os interesses ligados à cada campo (intelectual e político) para posteriormente verificar como e em que grau eles se manifestaram na estrutura dos decretos de fundação das Universidades. Deduzimos os interesses com base na bibliografia e nas fontes. Por meio do estudo das bibliografias no assunto e na análise das fontes (os decretos de fundação) nós buscamos mapear os interesses ligados a cada campo para em seguida conseguir identificar com mais clareza a forma como esses interesses se manifestaram na estrutura dos decretos das Universidades. A intensidade específica como se manifestaram os interesses particulares nos decretos revelaram o grau de autonomia e heteronomia de cada grupo no processo de construção das universidades.

Pela bibliografia podemos perceber qual foi o grande interesse de Vargas ao fundar instituições culturais. Segundo informações disponíveis no CPDOC, "Vargas não se cercou apenas de 'tenentes'. Sua política cultural envolveu a nomeação de intelectuais para postos de destaque e a criação de diversos órgãos capazes de atraí-los para junto do governo".

Bomeny fala sobre os interesses dos intelectuais de um modo geral: "As obras de arte como que absolvem fidelidades escusas às políticas públicas. Desafiam a perspectiva funcionalista de pensar a relação dos intelectuais com o poder. As obras de arte têm o dom de desarrumar esse esquema", mas este trecho mostra como que apesar

\footnotetext{
${ }^{3} \mathrm{http} / / /$ www.cpdoc.fgv.br/nav_historia/htm/anos30-37/ev_inteest001.htm data de acesso: 23 de junho 2009. Ver também Fávero (1980).
} 
de seus interesses, eles eram sufocados pela burocracia "Os intelectuais da educação não gozam dessa mesma chance de absolvição. Intelectuais, criadores e política agora se confundem, porque as idéias, as formulações, implicam implementação, implicam o xeque do mundo real". 4

A identificação dos interesses dos intelectuais se torna mais evidente durante a discussão sobre a legitimidade da UDF, Fávero afirma: "Tanto no decreto que institui a universidade, quanto no discurso de seu fundador, por ocasião da abertura dos cursos, o princípio de autonomia e liberdade é focalizado"s; podemos verificar nessa citação como a autora também identifica, com base nos documentos, que o interesse característico do campo intelectual é a autonomia de práticas científicas e artísticas, como havíamos mostrado na parte anterior.

Pela bibliografia podemos dizer que o principal interesse produzido pelo campo político foi o de cooptar os intelectuais ao passo que o principal interesse dos intelectuais foi a "liberdade de espírito", isto é, produzir ciência, arte, etc. sem a intervenção de forças externas.

Nas fontes isso fica ainda mais evidente. Analisando os documentos separamos em dois grupos as informações referentes à USP e UDF, o Grupo 1 diz respeito a informações que denotam uma maior autonomia da Universidade em relação ao governo, o Grupo 2 é o contrário.

\section{$\mathrm{USP}^{6}$}

$\mathrm{UDF}^{7}$

\footnotetext{
${ }^{4}$ Op. Cit. p. 22 e 23.

${ }^{5}$ Op. Cit. p. 80.

${ }^{6}$ Ver: Decreto n. 6.283 de 25/01/1934.

${ }^{7}$ Ver: Decreto n. 5.513 de 4/04/1935.
} 


\begin{tabular}{|c|c|}
\hline $\begin{array}{l}\text { Mais } \\
\text { autonomia } \\
\text { dos } \\
\text { intelectuais }\end{array}$ & $\begin{array}{l}\text { Menos } \\
\text { autonomia } \\
\text { dos } \\
\text { intelectuais }\end{array}$ \\
\hline Art. $3^{\circ}$ & Art. $27^{\circ}$ \\
\hline Art. $43^{\circ}$ & Art. $29^{\circ}$ \\
\hline Título III & Art. $52^{\circ}$ \\
\hline Título VII & Título VI \\
\hline
\end{tabular}

\begin{tabular}{|c|c|}
\hline $\begin{array}{l}\text { Mais } \\
\text { autonomia } \\
\text { dos } \\
\text { intelectuais }\end{array}$ & $\begin{array}{l}\text { Menos } \\
\text { autonomia } \\
\text { dos } \\
\text { intelectuais } \\
\end{array}$ \\
\hline Art. $2^{\circ}$ & Art. $21^{\circ}$ \\
\hline \multirow[t]{5}{*}{ Art. $18^{\circ}$} & Art. $26^{\circ}$ \\
\hline & Art. $38^{\circ}$ \\
\hline & $\begin{array}{l}\text { Art. } \quad 40^{\circ} \\
\text { (tópico 9) }\end{array}$ \\
\hline & Art. $44^{\circ}$ \\
\hline & Art. $45^{\circ}$ \\
\hline
\end{tabular}

Primeiramente analisaremos a UDF. Em seu decreto percebemos que grande parte dos dados contidos no Grupo 1 estão ligados à autonomia e liberdade de espírito. Verificando o Art. $2^{\circ}$ da UDF, os fins da Universidade estão claramente voltados para a produção científica e artística. O Art. $18^{\circ}$ fala mais sobre personalidade jurídica e autonomia didática e administrativa. Por outro lado, todos os artigos do Grupo 2 da UDF falam sobre como o governo possui direitos de nomear cargos administrativos importantes, como o de Reitor.

No caso da USP a estrutura se repete: principalmente no Art. $3^{\circ}$ e o Título III, fala sobre a autonomia científica, didática e administrativa. $\mathrm{O}$ Art. $3^{\circ}$ apresenta elementos muito próximos do Art. $2^{\circ}$ do decreto da UDF. Também muito próximo à UDF, os dados separados no Grupo 2 do decreto de fundação da USP delega ao governo o monopólio sobre a nomeação de cargos chave. ${ }^{8}$

Essa comparação nos leva ao mesmo raciocínio que tivemos na análise da bibliografia: o interesse do campo político é com relação à nomeação dos cargos ao passo que o interesse do campo intelectual é a autonomia de produção. Constatados os interesses,

${ }^{8}$ Ver Art. $27^{\circ}$ e $29^{\circ}$ principalmente. 
podemos perceber em que medida cada um dos grupos teve relevância na construção das Universidades. Percebemos que existia um lugar nos decretos para a autonomia científica o que denota uma influência do poder intelectual na construção dos decretos.

Nossa tese de que os interesses dos intelectuais tinham alguma relevância no processo de construção das Universidades pode ser comprovada comparando o local dos interesses políticos e intelectuais em cada decreto e a situação política dos estados.

Analisando os decretos notamos que UDF tinha muito menos autonomia do que a USP. No decreto da USP verifica-se grande apelo à autonomia interna da Universidade, fato que é pouco citado no decreto da UDF. A presença de um título inteiro dedicado à autonomia da USP (Título III) e um apelo à formação de um "espírito Universitário" produzido unicamente entre os atores da própria Universidade (Título VII) denota a maior presença dos interesses intelectuais na formação da USP. Ao contrário na UDF somente o Art. $2^{\circ}$ e $18^{\circ}$ dá a entender uma autonomia. Também podemos notar uma maior ênfase na ação do governo em relação aos cargos chave da UDF, fato que não é muito mencionado no decreto da USP, apesar de existir. Em suma, podemos inferir pelos decretos que a USP era mais autônoma do poder político do que a UDF, dito de outra forma, a classe intelectual de SP teve mais poder que a classe intelectual do RJ.

Acreditamos que essa diferença de autonomia entre as duas Universidades ocorre porque toda a classe política paulista estava enfraquecida após a revolução de 32 . Isso fez com que os políticos paulistas abrissem maiores concessões aos intelectuais no momento da fundação da Universidade. O contrário ocorreu no RJ, em que a classe política estava se fortalecendo cada vez mais. Ou seja, os interesses dos intelectuais estão presentes nos dois casos, a prova disso é que eles se tornam mais evidentes quando a classe política está mais fraca.

O que é importante salientar para continuar a análise é que existem duas economias agindo ao mesmo tempo no espaço social: 
uma economia do campo político e outra do campo econômico; de forma que cada uma produz um interesse específico, possui uma lógica específica e é dotada de uma força específica na sociedade ou de uma participação maior na construção do todo social. Agora veremos como a síntese desses dois interesses se objetivou em forma de Universidade.

\section{Reificação dos interesses em forma de instituição de ensino}

Iniciaremos esta parte analisando a formação das Universidades levando em conta somente os interesses produzidos no campo político, em um segundo momento incluiremos no modelo os interesses intelectuais.

Em 1932, São Paulo revoltou-se contra o processo de centralização do poder empreendido por Getúlio Vargas, pois esta centralização implicaria em uma perda de influência do estado paulista no território brasileiro.

Neste contexto histórico e tomando como elemento de análise unicamente o interesse político, podemos entender a fundação da USP e da Escola Livre de Sociologia e Política de São Paulo sob dois aspectos: uma tentativa de formar pessoal especializado e uma tentativa de cooptar lideranças.

A Escola Livre de Sociologia e Política de São Paulo tinha claramente o objetivo de formar uma elite especializada ou políticos profissionais para a luta política. Falando sobre as derrotas do estado paulista, o manifesto de fundação da ELSPSP explicita: "Dentre eles, entretanto, destaca-se naturalmente, por seu caráter básico, a falta de uma elite numerosa e organizada, instruída sob métodos científicos, ao par das instituições e conquistas do mundo civilizado, capaz de compreender antes de agir o meio social em que vivemos".

No entanto, a formação das Universidades tinha para o campo político um interesse mais profundo e importante do que a formação dos espíritos sob um conceito específico. Elas foram um local no qual

${ }^{9}$ Ver ANEXO: Manifesto de fundação da ELSPSP. 
os estados conseguiam criar vínculo com elites intelectuais através da distribuição de cargos.

As Universidades foram fundadas como "paióis de cargos", com isso queremos dizer que as Universidades funcionavam como espécies de celeiros do poder político, locais de onde o poder político dispunha e armazenava recursos a serem distribuídos com o objetivo de construir vínculos (como dissemos, os decretos mostram claramente o poder de nomeação de cargos chave que dispunha o governo). Desta forma a Universidade é um grande celeiro de cargos burocráticos. Sendo o interesse político a cooptação de uma elite intelectual, os políticos empreenderam a construção de locais em que poderiam distribuir cargos e consolidar relações de mando.

Se nos basearmos unicamente neste ponto de vista, perceberemos que as universidades (principalmente a USP e a UDF) foram produtos de uma luta propriamente política entre frações do campo político (principalmente Vargas e SP), produtos de interesses produzidos pelo campo político: desta forma poderíamos atribuir completa ou excessiva heteronomia ao campo intelectual diante de luta política e uma análise instrumental ou funcional da fundação das Universidade seria suficiente. No entanto, esta abordagem, como vimos, não é corroborado pelas fontes, pois estas mostram a influência que os intelectuais tiveram na formação das Universidades.

Como viemos defendendo não é possível explicar a formação das Universidades tendo como foco de análise somente o interesse produzido dentro do campo político. Isso se torna mais evidente quando formulamos a seguinte questão: por que a força política ou o interesse político construiria Universidades para cooptar as lideranças intelectuais? Por que ele não aproveitou instituições que já existiam? Ou ainda, por que não construiu outros tipos de paióis de cargos (hospitais, escolas, etc.)? Por que Universidades?

Vimos anteriormente que o principal interesse produzido pelo campo intelectual era a produção de arte, ciência, etc. Desta forma, o poder político, se quisesse cooptar os intelectuais, deveria utilizar a isca correta. Deveria produzir um paiol de cargos que atraísse essas 
lideranças, algo que os intelectuais julgassem interessante. Mas ao mesmo tempo, não poderia abrir demasiadas concessões sob pena de não conseguir manter o controle sobre eles.

Assim, percebemos como, de uma forma mais sutil, o interesse intelectual permeou as decisões no campo político, ou seja, pelo menos, teve-se que levar em conta os interesses intelectuais no processo de construção da instituição específica (no caso, foram as Universidades).

Por isso percebemos nos documentos, como já dissemos acima, que ao mesmo tempo em que os cargos burocráticos eram nomeados (principalmente o de Reitor) existia a autonomia de produção de conhecimento, ou seja, por um lado o poder político se beneficiava, por outro se limitava, em relação inversamente proporcional ao poder intelectual. Assim, podemos dizer que ao mesmo tempo em que os intelectuais tinham uma liberdade de espírito, o poder político tinha o monopólio das concessões dos cargos (no decreto da USP existe um Título inteiro - Título VII sobre o espírito universitário, o qual menciona como as relações internas devem se desenvolver livremente, o convívio entre professores e alunos, etc., por exemplo).

A fundação das Universidades ocorreu na exata medida em que foi produzido uma espécie de capital ambígua, algo que levasse em conta ao mesmo tempo os interesses do campo intelectual e do campo político. De fato, as Universidades foram a síntese desses dois interesses, como dissemos acima, o produto de uma ligação entre ambos em que cada interesse compartilhava parte de si para completar o todo, havendo, obviamente, a predominância de um em detrimento do outro. A síntese dessa reação de interesses foram as Universidades, elas são a forma física do contato/choque de interesses subjetivos.

Verificamos que o interesse político estava na formação de paióis de cargos, e o interesse intelectual na formação de lugares que possibilitassem o estudo e a pesquisa. Afirmamos que a Universidade é fundada como um centro que produz um interesse ambiguo, por ser 
ela a síntese destes dois interesses (político e intelectual). A Universidade poderia ser definida como um local de interesses vinculados ao mesmo tempo aos cargos e à produção científica/artística.

\section{$O$ caso da UDF}

A UDF é um exemplo de como os interesses intelectuais estão presente na construção das Universidades. A UDF teve vida curta e a sua implantação foi difícil, pois havia denúncias de que a Universidade tinha uma autonomia nas suas divisões que não eram previstas pela lei; ela só foi implementada por Vargas para evitar que ocorressem indisposições com Anísio Teixeira ${ }^{10}$. O momento favoreceu a implementação da UDF porque Vargas ainda necessitava do apoio dos intelectuais, desta forma a Universidade foi implementada com certa liberdade intelectual.

Conforme a classe política do RJ se fortaleceu os intelectuais que reclamavam autonomia perderam poder relativo (eles não perderam poder absoluto, mas apresentaram-se mais fracos diante do fortalecimento do poder político), e o enfraquecimento da classe intelectual levou ao fim da UDF.

$\mathrm{O}$ fechamento da UDF ocorreu justamente quando a força política se fortaleceu ao ponto de englobar a autonomia aos intelectuais "Não resta dúvida de que o fato de a UDF ter nascido num momento em que o país caminhava a largos passos para um fechamento cada vez maior em termos ideológicos e para a implantação declarada de um regime autoritário, fez com que sua presença, enquanto instituição se tornasse incômoda" ${ }^{11}$. A presença da UDF era incômoda justamente pela autonomia intelectual que ela reclamava."Mais uma vez lembramos que a implantação da UDF, dentro do contexto que antecedeu o Estado Novo, foi, sem dúvida, um desafio. Desafio por se tratar de uma instituição universitária

\footnotetext{
${ }^{10}$ Op. Cit. p. 70.

${ }^{11}$ Op. Cit. p. 79.
} 
constituída de escolas e institutos voltados principalmente para as ciências humanas, tendo uma linha de pesquisa e de confrontos com a realidade e não com um objetivo de ser mera agência de ensino, preocupada com a transmissão ou repetição de um saber constituído e com a manutenção do status quo". ${ }^{12}$

A conclusão que chegamos observando o caso específico da UDF é que não seria possível a construção da Universidade caso só estivesse em jogo o interesse político, os interesses intelectuais relativamente autônomos eram necessários para a construção da Universidade e isso se confirma no momento em que os intelectuais perdem poder relativo (devido o aumento do poder político). A perda de poder relativo dos intelectuais levou ao fim da UDF, este fato denota a importância da autonomia relativa dos intelectuais no processo de construção das Universidades, as Universidades não foram produto exclusivo do interesse político. Assim, não podemos falar em uma heteronomia completa do campo intelectual em relação a política.

\section{Conclusão}

Nossa tese de heteronomia relativa do campo intelectual em relação ao campo político em oposição à tese de heteronomia completa ou excessiva se fortalece ao percebermos, por meio dos documentos, a baixa autonomia da UDF em relação a USP, levando em consideração a força política de cada local: o volume de força política em cada estado condicionou o índice de maior ou menor abertura para os interesses intelectuais, que pode ser evidenciada pela maior ou menor autonomia das universidades.

A USP tinha mais autonomia formal do que a UDF talvez por que SP estava enfraquecido politicamente, neste sentido os interesses intelectuais estiveram mais relevância (denunciada pela ênfase maior na liberdade de pesquisa e ensino, com a criação de um espírito próprio e a presença de um Título inteiro do decreto dedicado à

${ }^{12}$ Op. Cit. p. 81 e 82. 
autonomia). O contrário ocorreu na UDF: a palavra autonomia quase não é pronunciada e o decreto enfatiza mais a relação entre o governo e os cargos burocráticos, fato que pode ser justificado pela maior força da classe política no estado.

A análise centrada unicamente nos interesses políticos não pode explicar o fato da construção de Universidades, seria preciso levar em conta (pelo menos de uma forma passiva) os interesses dos intelectuais, para que as políticas conseguissem utilizar a isca certa para os interesses específicos. Nesse sentido, não poderíamos explicar a construção das Universidades sem levar em conta os interesses intelectuais.

O caso específico da UDF é um bom exemplo para pensarmos a relação entre o campo político e o campo intelectual. Em um primeiro momento, enquanto a classe política ainda estava fraca, foi possível a implementação dos interesses intelectuais: fundação da UDF com algumas disposições autônomas. Em um segundo momento, após o fortalecimento da classe política, a UDF foi extinta, pois os intelectuais perderam poder relativo. Através deste caso conseguimos entender tanto a qualidade dos interesses dos intelectuais (autonomia) e dos políticos (cooptação) como a forma que se manifestam a síntese dos interesses intelectuais e políticos formando a Universidade. A Universidade só foi fundada quando havia alguma força relativa na classe intelectual, após o seu enfraquecimento em relação à classe política, a UDF foi fechada.

A constatação empírica da heteronomia relativa do campo intelectual ainda ajuda a formular hipóteses teóricas. A conjugação dos interesses no momento de criação das Universidades permite lançar a hipótese de que as Universidades são locais onde se produz um interesse ambíguo (ligado, ao mesmo tempo, aos cargos e às ciências e artes), hipótese que não pode ser formulada se olharmos para a predominância exclusiva do campo político no processo de formação das Universidades. 


\section{BIBLIOGRAFIA}

BOMENY, Helena. Infidelidades eletivas: intelectuais e política. In: Helena Bomeny (Org.). Conselação Capanema: intelectuais e política. Rio de Janeiro, FGV, Bragança Paulista, Ed. Universidade de São Francisco, 2001.

BOURDIEU, Pierre. As regras da arte: gênese e estrutura do campo literário. São Paulo, Companhia das Letras, 1996.

CAPELATO, Maria Helena. Propaganda política e controle dos meios de comunicação. In: PANDOLFI, Dulce (org). Repensando o Estado Novo. Rio de Janeiro, FGV, 1999.

FÁVERO, Maria de Lourdes de A. Universidade \& Poder: análise crítica/fundamentos históricos: 1930-45. Rio de Janeiro, Achimé, 1980.

CODATO, Adriano; GUANDALINI, Walter. Os autores e suas idéias: um estudo sobre a elite intelectual e o discurso político do Estado Novo. Estudos Históricos. Rio de Janeiro, v. 32, p. 145-164, 2003.

MICELI, Sérgio. A política cultural. In: PANDOLFI, Dulce (org). Repensando o Estado Novo. Rio de Janeiro, FGV, 1999. p. 191-196. . Imagens negociadas: Retratos da elite brasileira (1920-1940). São Paulo, Cia. das Letras, 1996.

\section{ANEXOS}

Decreto 6283/34 | Decreto No 6.283, de 25 de janeiro de 1934 do São Paulo $25 / 01 / 1934$

Cria a Universidade de São Paulo e dá outras providências

O DOUTOR ARMANDO DE SALLES OLIVEIRA, Interventor Federal no Estado

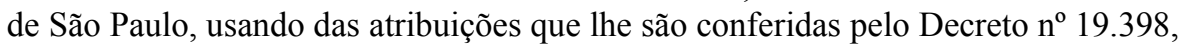
de 11 de novembro de 1930, e considerando que a organização e o desenvolvimento da cultura filosófica, científica, literária e artística, constituem as bases em que se assentam a liberdade e a grandeza de um povo; 
considerando que, somente por seus institutos de investigação científica, de altos estudos, de cultura livre, desinteressado, pode uma nação moderna adquirir a consciência de si mesma, de seus recursos, de seus destinos;

considerando que a formação das classes dirigentes, mormente em países de populações heterogêneas e costumes diversos, está condicionada à organização de um aparelho cultural e universitário, que ofereça oportunidade a todos e processe a seleção dos mais capazes;

considerando que, em face do grau de cultura já atingido pelo Estado de São Paulo, com Escolas, Faculdades, Institutos de formação profissional e de investigação científica, é necessário e oportuno elevar a um nível universitário a preparação do homem, do profissional e do cidadão,

Decreta:

Da Universidade de São Paulo

Artigo 1. - Fica criada, com sede nesta Capital, a Universidade de São Paulo.

Artigo 2. - São fins da Universidade:

a) promover, pela pesquisa, o progresso da ciência;

b) transmitir pelo ensino, conhecimentos que enriqueçam ou desenvolveram o espírito, ou sejam úteis à vida;

c) formar especialistas em todos os ramos da cultura, e técnicos e profissionais em todas as profissões de base científica ou artística;

d) realizar a obra social de vulgarização das ciências, das letras e das artes, por meio de cursos sintéticos, conferências, palestras, difusão pelo rádio, filmes científicos e congêneres.

\section{TÍTULO II \\ Da composição da Universidade}

Artigo 3. - A Universidade de São Paulo se constitui dos seguintes institutos oficiais:
a) Faculdade De Direito;
b) Faculdade De Medicina;
c) Faculdade De Farmácia E Odontologia;
d) Escola Politécnica;
e) Instituto De Educação;
f) Faculdade De Filosofia, Ciências E Letras; 
g) Instituto De Ciências Econômicas E Comerciais h) Escola de Medicina Veterinária i) Escola Superior de Agricultura;

j) Escola de Belas Artes.

Parágrafo único - as instituições enumeradas neste artigo são autônomas dentro das normas do presente decreto e podem expedir certificados, diplomas e conferir grau nas diversas atividades profissionais.

(Nota do editor: os artigos entre 4 e 23 foram suprimidos)

\section{CAPÍTULO VI TÍTULO III Da Autonomia e do Patrimônio da Universidade}

Artigo 24 - A Universidade de São Paulo (em personalidade jurídica, autonomia científica, didática e administrativa, nos limites do presente decreto, e, uma vez constituído um patrimônio com cuja renda se mantenha, terá completa autonomia econômica e financeira.

Parágrafo único - Ficam respeitados os patrimônios atuais das Escolas, Faculdades ou Institutos da Universidade, e os que forem instituídos com destino especial, para que sejam aplicados exclusivamente de acordo com a sua constituição.

Artigo 25 - O patrimônio da Universidade de São Paulo será constituído:

1) das subvenções dos poderes públicos;

2) de donativos particulares;

3) de terrenos e prédios em que funcionam, com as suas respectivas instalações, os seus Institutos, Escolas e Faculdades.

§ 1. - O patrimônio da Universidade poderá, no todo, ou em parte, ser alienado, para ter nova aplicação, dentro da mesma finalidade, mediante aquiescência, por dois terços dos votos do Conselho, e aprovação pelo Governo do Estado.

§ 2. - O Governo do Estado, a partir de 1934, depositará anualmente, para constituição desse patrimônio, a importância que, para esse fim, for consignada no orçamento.

\section{TÍTULO IV}

\section{Da direção e administração da Universidade}

(Nota do editor: o artigo26 foi suprimido) 
Artigo 27 - O reitor da Universidade, escolhido pelo governo dentre uma lista de três nomes de professores catedráticos, eleitos pelo Conselho Universitário, será nomeado por dois anos. decreto.

Parágrafo único - O processo de eleição é o designado no artigo 29 deste

(Nota do editor: o artigo28 foi suprimido

Artigo 29 - O diretor de cada uma das escolas e faculdades que participam da Universidade será nomeado por dois anos pelo governo numa lista de três nomes de professores catedráticos em exercício, votados, em escrutínio secreto, pela Congregação presente, nos termos seguintes:

a) cada professor votará numa cédula com três nomes;

b) considera-se, em cada cédula, votado em primeiro turno, o nome que estiver em primeiro lugar, e, em segundo, os demais c) constarão da lista os nomes, votados em primeiro turno, que alcançarem um terço do total de votos da Congregação, desprezadas as frações;

d) se não houver três nomes escolhidos em primeiro turno, serão indicados, até compor a lista tríplice, os mais votados em segundo.

Parágrafo único - Não se permitem votos por procuração.

(Nota do editor: os artigos entre 30 e 42 foram suprimidos)

Artigo 43 - A medida que as condições financeiras do Estado o permitirem, e de acordo com a natureza da cadeira, será adotado para os professores e seus auxiliares, o regime de tempo integral, para que se possam dedicar exclusivamente aos seus trabalhos científicos e as suas funções docentes na Universidade.

\section{TÍTULO VI \\ Das missões de professores e das bolsas de viagens e de estudos}

Artigo 44 - O Governo do Estado poderá, sob proposta do Conselho Universitário:

a) comissionar no estrangeiro, para especializações e aperfeiçoamento técnico, professores e auxiliares de ensino;

b) contratar, para a inauguração, instalação ou regência de cursos, pelo tempo que for necessário, professores estrangeiros de notória competência nas matérias para as quais não se encontrarem especialistas no país;

c) promover o intercâmbio de professores da Universidade com os institutos universitários do país e do estrangeiro; 
Artigo 45 - Ficam instituídas para a Universidade de São Paulo, bolsas de viagem ou de estudos, para o fim de proporcionar os meios de especialização e aperfeiçoamento, em instituições do país e do estrangeiro, a professores e auxiliares de ensino, os diplomados pela Universidade de São Paulo, que tenham revelado aptidões excepcionais.

§ 1. - Para esse fim, será incluída, anualmente, no orçamento do Estado, verba necessária, que será recolhida a uma caixa especial e aplicada pelo reitor da Universidade, mediante proposta de diretores das Faculdades, Escolas e Institutos, e aprovação do Conselho Universitário;

$\S 2$ 2. - Entre a Universidade de São Paulo e os escolhidos, cada ano, nos termos deste artigo, serão convencionados os objetivos das viagens do estudo, ou pensionato, o tempo de permanência, a pensão e as obrigações a que ficam sujeitos.

$\S 3$. - Poderá ser anulada a concessão de bolsa, quando o procedimento ou o aproveitamento do enviado não for satisfatório, a juízo do Conselho Universitário.

Artigo 46 - Os diretores dos diferentes institutos universitários poderão dispensar das taxas de matrícula, cada ano, alunos pobres, de reconhecido merecimento, até o limite máximo fixado pelos respectivos regimentos.

\section{TÍTULO VII Do espírito universitário}

Artigo 47 - Para a criação de um ambiente e uma tradição de espírito universitário, serão adotados meios de desenvolver o espírito de iniciativa, de trabalho e de pesquisa, a união e solidariedade de professores, auxiliares de ensino, e dos antigos e atuais alunos das diversas Faculdades, Escolas e Institutos, na defesa da eficiência e do prestígio das instituições universitárias.

Parágrafo único - A aproximação e o convívio dos professores e alunos das diversas Faculdades Escolas ou Institutos, serão promovidos especialmente:

a) pela proximidade dos edifícios e construção de vilas universitárias;

b) pela centralização administrativa da Universidade, em todo quanto respeite ao interesse comum;

c) pela criação de cursos comuns, que atendam às necessidades de alunos de diferentes Faculdades, Escolas ou Institutos; cooperação;

d) pelo regime de seminários, centros de debates e trabalho em

e) pela prática de atividades sociais em comum, pelos alunos das diferentes Faculdades, Escolas ou Institutos; 
f) pela organização da sociedade e clubes universitários, de estudos, de jogos e de recreação;

g) pela prática habitual de esportes, jogos atléticos e competições de que participem universitários das diferentes Faculdades, Escolas ou Institutos.

(Nota do editor: os artigos entre 48 e54 foram suprimidos)

\section{ARMANDO DE SALLES OLIVEIRA}

Cristiano Altenfelder Silva

Publicado na Secretaria de Estado da Educação e da Saúde Pública, São Paulo aos 25 de janeiro de 1934. A. Meirelles Reis Filho, Diretor Geral. 